Peter J. Schulz \& Sara Rubinelli

\title{
INTERNET-ENHANCED HEALTH COMMUNICATION
}

\section{Introduction}

The figure that stands at the origin of two considerably different areas of knowledge is Hippocrates (ca $460 \mathrm{BC}-370 \mathrm{BC}$ ). In the historiography of sign theories Hippocrates is considered to be at the same time the "father of medicine" and the "father of semiotics" (Kleinpaul 1972: 103). His role as the father of medicine is not so much due to the Hippocratic Oath, which he probably did not compose, as it is due to his analytic approach that moved ancient medicine beyond its partly philosophical, partly superstitious roots (Garrison 1960). As the "father" or "master of all semiotics", Hippocrates introduced the distinction, still widely accepted today, between two types of messages, "conventional" and "natural". While the former are defined as those whose power to signify is thought to depend on some prior agreement, the latter signify in an agreement-independent, general way. As Hippocrates put it, the natural messages "prove to have the same significance in Lybia, in Delos, and in Scythia" (Hippocrates 1923: Prognostic XXV). Given the quasi-universality of this class of nonverbal messages, which physicians call symptoms, Hippocrates drew the conclusion "that one should be right in the vast majority of instances, if one learns them well and knows how to estimate and appreciate them properly."

Medicine, as the emblematic ancestral field of semiotics, has also provided the first definition of 'sign' as a medical symptom. The semiotic perspective in medicine has mainly to do with the concept of diagnosis: in establishing the relation between a symptom and a disease-category one refers to the symptom as a sign. A medical-diagnostic process is a form of categorization, where the doctor tries to find an answer to the following question: "To which disease-category do I attribute this patient with these symptoms, or is there no disease (as a category) present here, or does the symptom ambiguously refer to more diseases?" (Gale and Marsden 1985). The selection and attribution of symptoms to disease-categories, then, implies a process of interpretation and thus requires also a semiotic perspective. This prominence of medicine in the semiotic horizon still persists todays.

Many prominent authors, among them Ogden and Richards (1923: 21) as well as Thomas A. Sebeok (1994, 44-60), refer to sign theory within the practices of a doctor who is diagnosing the disease of a patient by noting symptoms, such as his temperature (cf. Staiano-Ross 2009a, 2009b, 2009c). While, on the one hand, the idea of semiotics as a theory of interpreting symptoms in order to arrive at an appropriate prognosis remains, the idea that semiosis is not just a process of interpreting signs but was also the communicative process between a doctor and the patient has suffered relative neglect. We know for certain that the reputation of Hippocrates was based on his ability to consider the special situation of the patient as well as his surroundings, relatives and other dependants. As Sebeok $(1994,9)$ has pointed out, referring to the ancient medical science of Hippocrates:

The craft of interpreting symptoms has a significance far exceeding the practitioner's day-to-day management of sickness. As Hippocrates had already 
anticipated, its success derives from its psychological power, which critically depends on the practitioner's ability to impress his/her skills on both the patient and their joint environment (the audience gathered in his/her workshop, which may consist of the patient's family and friends, as well as the practitioner's colleagues and staff).

Through the Internet this 'communicative aspect' of semiosis comes to the fore in several respects. And this applies particularly to the area of Internet-Enhanced Health Communication, the topic of the present special issue. First, Internet-Enhanced Health Communication as an independent field testifies to the growing interest in the way health-related messages - messages, in a semiotic sense, as texts made up of signs - can be transmitted and received effectively. Second, different eHealth tools allow and intensify significantly the way consumers and patients can seek for health information. Third, instead of the traditional way of delivering information in "one-size-fits-all approaches", Internet-Enhanced Health Communication allows a personally and contextually tailored way of reaching the audience. Overall, the internet potentially enhances consumers' and patients' ability to make sense of their health-related issues.

All these and other semiotic aspects of Internet-Enhanced Health Communication are at stake in the contributions of this special issue. Similarly, the new forms of communication that eHealth tools do offer, also entail certain risks that a semiotic perspective of communication can reveal. Some of the articles and essays in this issue take a general approach to internet-driven health communication; some address specific issues from that field. We proceed from the general to the specific.

Linda Neuhauser and Gary L. Kreps are situated on the "general" end of the continuum. They start by mentioning the great potential of health communication interventions, only to take note of the fact that they have often failed in the past. Problem areas include the weakness of a theoretical foundation of health behavior models, disregard for individual and contextual factors, limits to interactivity, and failure to achieve the vast reach of mass communication and the effectiveness of interpersonal communication at the same time. This leads the authors to discuss the potential of social semiotics to improve health communication interventions. They discuss this potential at some length while reviewing the problem areas of traditional interventions. They then proceed to review eHealth issues and evidence related to information-seeking and patient-provider communication; major systematic reviews and single-study examples of dietary, physical activity, and weight loss interventions; and they give general examples of interventions in other health areas. In summary, it appears that on balance "eHealth information that is more personally and contextually tailored motivates and supports people to make better decisions than traditionally static and one-size-fits-all approaches."

Grazia Orizio and Umberto Gelatti move from the general to the specific within their article. They discuss the implications for public health of the establishment and rising popularity of the internet. They present arguments from the perspectives of health professionals, health organizations and patients, and put special emphasis on purchasing health services online, particularly drugs. The article starts with a concise summary of the implications the internet has for public health, reviewing the basic facts and well-known arguments. It then proceeds to the issue of online pharmacies. The problematic aspects are counterfeit drugs being sold over the web, as well as the overcoming of prescription regulations and restrictions. The results of a semiotic analysis of selling arguments 
shows that most arguments can be grouped into two classes: those promoting the advantages of buying the drug and those touting the low risk involved. All in all, the arguments are not very different from those used in the selling of other commodities. That, however, is the problem, of course, since medical drugs are different from other goods. Reviewing the doctor-patient relationship in the online selling of prescription drugs (which is often non-existent or just a pretense) and the legal and economic issues involved, the authors suggest there is an urgent need for regulation, despite the difficulties that they anticipate in achieving it.

Free health information on the web rather than commercial sales is the major focus of Miriam Locher. She is particulary concerned with a format that is well known from print media, advice columns. Based on pertinent research and her own investigations, Locher starts out by discussing, in linguistic terms, delicate acts of advice giving and advice seeking. Both acts are shown as possessing a 'face-threatening' character. Then the format of the advice column is considered. As the speech act of advice is exerted with care, and often indirectly, mitigation appears to be a central quality of a typical advice column text. In the next step, Locher describes how the advice column format can acquire particular benefits if it is used online. These benefits include availability and anonymity, personal appeal, identification potential, the possibility of reaching many with a "personalized" response, the possibility of adapting the text to the needs of the target group, and the potentialities of archiving and hyperlinking. The article ends by reviewing the limits and challenges to the format, among which are the danger that archived advice may become outdated and the restriction to one exchange - the advice giver cannot ask the seeker questions.

Maria Caiata Zufferey and Peter J. Schulz study patients' use of the interactive sections of a patientcentred website called "Oneself," specifically designed to provide information and support for patients with chronic low back pain, and to help them cope with their ailment. The authors' focus is thus on a particular online health communication intervention which includes several synchronous and asynchronous tools that allow users to interact with health professionals and lay people. There is, among other sections on the website, also a library of informative texts and a gym section, with illustrated exercises. Users' reactions to the site were analysed quantitatively and qualitatively. Quantitatively, the log files of 276 users were looked at. Qualitatively, the authors conducted semistructured interviews with a sample, for convenience's sake, of 18 users. An inductive thematic analysis was used to code every interview and to link and group the identified codes into larger categories. Results confirm the perceived utility of a user-centred interactive website monitored by health professionals as a venue for self-management education among individuals with chronic illness. However, they also suggest that to achieve their full potential, such interactive services must possess several features such as credibility, multimediality, usability and dynamism (the rapidity of answers given to queries, the continual updating of the website, the regularity of a newsletter), and have to be designed taking into account the type and the stage of the illness, as well as the sociodemographic characteristics of the patients. The article also discusses why users were not particularly enthusiastic about lay and synchronous interaction (chat room).

The remaining two articles focus on the communication by care providers and the communication by advice seekers. Nancy L. Green introduces and discusses a computer system that was designed to assist healthcare providers by creating editable first drafts of letters that offer genetic counseling to patients. Due to the wide range of genetic conditions to be covered and the rapid growth of knowledge in genomic medicine, it would not be feasible to have human experts to pre-author all 
possible texts that might be needed. Therefore techniques for natural language generation of patient letters have been developed. To gain insight for the design of such a system, a corpus of genetic counseling patient letters was studied. Green's article describes the methods used to analyze expressions of uncertainty in the corpus, mentions some results of that analysis, and discusses the implications for natural language generation. Uncertainty is pervasive in genomic medicine because a patient's symptoms could be due to more than one underlying (genetic or non-genetic) condition, or the patient's test results may be a false positive, false negative, or ambiguous. Moreover, the health effects of a genetic mutation are uncertain due to several biological factors. The conclusion of the article identifies the problems of communicating uncertainty. The presentation of risk in indefinite terms may be desirable from a counseling point of view but it will be less than transparent. On the other hand, the presentation of a numeric probability may be misinterpreted by a lay reader or divert his/her attention from a more important point. Also, transparency requires that the probabilistic nature of genetic medicine be disclosed, but its disclosure may induce a lack of trust in the lay reader. These problems exist, no matter whether text is generated by humans alone or with the help of machines.

If Green is concerned with how medical care providers communicate, Paul Crawford, Kevin Harvey \& Brian Brown's focus is on how potential patients communicate. He uses corpus analysis to study a one million word collection of adolescent health emails submitted to an online health forum, the Teenage Health Freak. It is a UK-based website which provides evidence-based health advice and information for young people. The corpus approach to linguistic analysis integrates both quantitative and qualitative techniques. By examining the common ways in which adolescents construct their health concerns to professionals online, this study aims to describe young people's accounts of mental health (depression-related issues in particular), thereby giving voice to an age group whose subjective experiences of mental health problems have often been overlooked in favour of older generations. The article begins by describing the special challenges to health communication in caring for adolescents. It then describes methodology and presents results. Concluding, the article argues that, contrary to widespread beliefs, young people are not necessarily likely to possess limited knowledge about what constitutes a treatable mental health problem. Much of the data in the study appears to show that adolescents' conceptions of mental health issues are significantly broader than those elicited in previous studies. As Western societies have learned to take depression more seriously as an illness, so did the youngsters who voiced their concerns on the website studied. The other side of the coin is also formulated: A general trend of psychiatrisation in our societies may help to account for the adolescents' commonly articulating their distress in clinical terms.

\section{References}

Gale, J. \& Ph. Marsden (1985). Diagnosis: Process not product. In: M. Sheldon, J. Brooke, and A. Rector (eds.), Decision-Making in General Practice, London: Macmillan Press, 59-105.

Kleinpaul R. (1972 [1888]). Sprache ohne Worte: Idee einer allgemeinen Wissenschaft der Sprache. The Hague: Mouton.

Ogden, C.K. and I.A.Richards (1923). The Meaning of Meaning. New York: Harcourt, Brace. 
Sebeok, Th. A. (1994). Signs. An Introduction to Semiotics. Toronto: University Press.

Staiano-Ross, K. (2009a). Galen. In: P. Cobley (ed.), The Routledge Companion to Semiotics. London: Routledge.

Staiano-Ross, K. (2009b). Hippocrates. In: P. Cobley (ed.), The Routledge Companion to Semiotics. London: Routledge.

Staiano-Ross, K. (2009c). Medical semiotics. In: P. Cobley (ed.), The Routledge Companion to Semiotics. London: Routledge. 